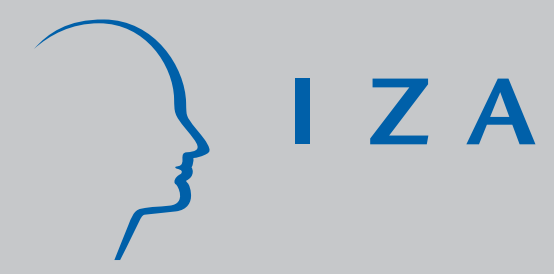

IZA DP No. 3049

Real Wage Rigidities and the Cost of Disinflations

Guido Ascari

Christian Merkl

September 2007 


\title{
Real Wage Rigidities and the Cost of Disinflations
}

\author{
Guido Ascari \\ University of Pavia
}

Christian Merkl

IfW, University of Kiel

and IZA

\section{Discussion Paper No. 3049 \\ September 2007}

\author{
IZA \\ P.O. Box 7240 \\ 53072 Bonn \\ Germany \\ Phone: +49-228-3894-0 \\ Fax: +49-228-3894-180 \\ E-mail: iza@iza.org
}

\begin{abstract}
Any opinions expressed here are those of the author(s) and not those of the institute. Research disseminated by IZA may include views on policy, but the institute itself takes no institutional policy positions.
\end{abstract}

The Institute for the Study of Labor (IZA) in Bonn is a local and virtual international research center and a place of communication between science, politics and business. IZA is an independent nonprofit company supported by Deutsche Post World Net. The center is associated with the University of Bonn and offers a stimulating research environment through its research networks, research support, and visitors and doctoral programs. IZA engages in (i) original and internationally competitive research in all fields of labor economics, (ii) development of policy concepts, and (iii) dissemination of research results and concepts to the interested public.

IZA Discussion Papers often represent preliminary work and are circulated to encourage discussion. Citation of such a paper should account for its provisional character. A revised version may be available directly from the author. 
IZA Discussion Paper No. 3049

September 2007

\section{ABS TRACT}

\section{Real Wage Rigidities and the Cost of Disinflations ${ }^{*}$}

This paper analyzes the cost of disinflations under real wage rigidities in a micro-founded New Keynesian model. The consensus is that real wage rigidities can be a useful mechanism to induce the inflation persistence that is absent in the standard Calvo model. Real wage rigidities thus generate a slump in output after a credible disinflationary policy. This consensus is flawed, since it depends on analyzing the model in a linearized framework. Once nonlinearities are taken into account, the results change dramatically, both qualitatively and quantitatively. Real wage rigidities imply neither inflation persistence, nor output costs of disinflations. Real wage rigidities actually create a boom after a permanent reduction in the inflation target of the monetary policy.

JEL Classification: E31, E50

Keywords: disinflation, sticky prices, real wage rigidities, nonlinearities

Corresponding author:

Christian Merkl

Kiel Institute for the World Economy (IfW)

Düsternbrooker Weg 120

24105 Kiel

Germany

E-mail: christian.merkl@ifw-kiel.de

\footnotetext{
* We would like to thank Jean-Pascal Benassy, Jordi Galí, Paul J. Kramer, Tiziano Ropele, Leo von Thadden, Roland Winkler, the participants of the IfW Symposium on "The Phillips Curve and the Natural Rate of Unemployment," the Bundesbank-IWH workshop on "Monetary and Financial Economics" and the European Meeting of the Econometric Society in Budapest for very helpful comments.
} 


\section{Introduction}

Ball and Romer (1990) show that nominal rigidities need to be complemented by real rigidities in order to generate a suitable endogenous propagation mechanism of monetary policy. Indeed, it is well known that the widely used Calvo price staggering model is not able to generate inflation persistence, and it is believed that this shortcoming can be corrected by introducing real rigidities.

After the influential contribution of Hall (2005) a reduced form of a real wage rigidity assumption began to be incorporated in many dynamic stochastic general equilibrium (DSGE) New Keynesian models, starting with Krause and Lubik (2007) and applied in a number of papers (e.g., Blanchard and Galí, 2006, 2007, and Christoffel and Linzert, 2006). ${ }^{1}$ Most of these papers show that real wage rigidities are important to improve the model performance, and to explain the sluggish behavior of inflation.

It is therefore natural to think that real wage rigidities may be useful to explain the output costs of a disinflationary policy because they induce the inflation persistence that is absent in the standard Calvo model. For a recent example of this argument see Section 4 of Blanchard and Galí (2007). Indeed, this is certainly the case in the log-linearized model.

This paper, however, shows that it is not the case if nonlinearities are taken into account. While real wage rigidities generate an output slump under a disinflation in the log-linearized model, they lead to a boom in the nonlinear version of the model. The interaction between long-run effects and short-run dynamics leads, therefore, to completely different results in the linearized and in the nonlinear model. We show that real wage rigidities imply neither inflation persistence nor output costs after a disinflationary policy.

In contrast, the difference between the log-linear and the nonlinear model is only of quantitative nature when comparing the effects of real wage rigidities under a temporary shock. A temporary shock does not imply movement from one steady state to another. A disinflation, instead, implies a permanent change in the level of inflation. Thus, the effects of such a permanent shock cannot be analyzed using a version of the model that is log-linearized around one particular steady state.

\footnotetext{
${ }^{1}$ A similar reduced form would also be implied by the famous "gift-exchange model" of Akerlof (1984), or by other labor market analyses (e.g., Holden, 1994, Oswald, 1979).
} 
Some papers in the literature (e.g., Ascari, 2004, Yun, 2005) show that nonlinearities may play an important role in DSGE New Keynesian models. Here, we show that this is the case regarding the effects of real wage rigidities, an increasingly common feature embedded into New Keynesian models. Researchers should be aware of the potentially big mistake of inferring the effects of permanent shocks through log-linearized models.

The rest of this paper is structured as follows. Section 2 presents the model and its calibration. Section 3 compares the steady state effects in the linearized and nonlinear model. Section 4 analyzes the effects of real wage rigidities in a disinflation experiment, and does the same for a temporary shock to the inflation target. Section 5 shortly concludes.

\section{The Model and Calibration}

The model is a standard NK model where:

(i) Firms produce a differentiated product using the following simple constant returns production function

$$
Y_{i, t}=N_{i, t}
$$

where $Y$ is output and $N$ is the labor input. ${ }^{2}$

(ii) Firms' pricing is described by the usual Calvo mechanism, where $\theta$ is the fraction of firms not adjusting their price in any given period.

(iii) Households have the following instantaneous and separable utility function:

$$
U\left(C_{t}, N_{t}\right)=\frac{C_{t}^{1-\sigma}}{1-\sigma}-d_{n} \frac{N_{t}^{1+\varphi}}{1+\varphi},
$$

where $C$ is composite consumption (with elasticity of substitution between different types of goods equal to $\varepsilon$ ).

(iv) The following partial adjustment model for the real wage is assumed in order to introduce real wage rigidities à la Hall (2005):

$$
\frac{W_{t}}{P_{t}}=\left(\frac{W_{t-1}}{P_{t-1}}\right)^{\gamma}\left(M R S_{t}\right)^{1-\gamma}
$$

\footnotetext{
${ }^{2}$ Note that we choose the constant returns production function for expositional simplicity (the more general case is derived in the Appendix). Under diminishing returns, the differences between the linear and nonlinear model would even be more substantial. Results are available on request.
} 
where $M R S$ is the marginal rate of substitution between labor supply and consumption. For sufficiently big $\gamma$, this model implies a sluggish adjustment of the real wages. Note that this is the nonlinear counterpart of the partial adjustment model for the real wage employed in many of the references above. For example, in Blanchard and Galí (2007) assume $\hat{w}_{t}-\hat{p}_{t}=\gamma\left(\hat{w}_{t-1}-\hat{p}_{t-1}\right)+(1-\gamma) \widehat{m r} s_{t}{ }^{3}$

(v) The monetary policy for the nominal interest rate, $i_{t}$, is assumed to be described by a standard Taylor rule:

$$
\left(\frac{1+i_{t}}{1+\bar{\imath}}\right)=\left(\frac{\pi_{t}}{\bar{\pi}}\right)^{\alpha_{\pi}}\left(\frac{Y_{t}}{\bar{Y}}\right)^{\alpha_{y}}
$$

where $\pi_{t}$ is the gross inflation rate (i.e., $P_{t} / P_{t-1}$ ), $\bar{\pi}$ is the central bank inflation target, and $\bar{Y}$ is the corresponding steady state level of output. ${ }^{4}$

The Appendix describes all model equations in detail and our benchmark calibration, which is standard. The qualitative results do not depend on the calibration values chosen.

\section{$3 \quad$ Steady State Effects}

The obvious starting point to analyze a disinflation experiment is to look at the steady state of the full nonlinear model, which is easy to compute, as there is no need for any approximation (see Appendix). As shown by Ascari (2004) and Yun (2005), the long-run trade-off between steady state inflation and output is highly nonlinear in the New Keynesian framework. This is because two effects are at work. First, as firms set the price for current and future periods (according to the stochastic Calvo scheme), under a positive discount rate, current profits obtain a greater weight than future profits, and firms set a somewhat lower price than under a discount rate of zero. This timediscounting effect generates a weak positive inflation-output relationship.

Second, positive inflation increases price dispersion, which generates strong distortions in an economy with Calvo price staggering (see Graham and Snower, 2004, for a

\footnotetext{
${ }^{3}$ Throughout the paper, capital letters refer to levels, whereas small hatted letters denote the logdeviations from the steady state. Note, morever, that the degree of real rigitidies, i.e., $\gamma$, does not affect the steady state of the model, since in the steady state $\frac{W}{P}=M R S$, whatever the value of $\gamma$.

${ }^{4}$ Note that each steady state inflation rate is associated with a different level of output, as will be shown below.
} 
detailed explanation). In fact, aggregate employment is given by

$$
\begin{aligned}
N_{t} & =\left[\int_{0}^{1} N_{i, t} d i\right]=\left[\int_{0}^{1} Y_{i, t} d i\right]=\left[\int_{0}^{1}\left(\frac{P_{i, t}}{P_{t}}\right)^{-\varepsilon} Y_{t} d i\right]= \\
& =\underbrace{\int_{0}^{1}\left[\left(\frac{P_{i, t}}{P_{t}}\right)^{-\varepsilon}\right] d i}_{s_{t}}=s_{t} Y_{t} .
\end{aligned}
$$

Since $s_{t} \geq 1$, price dispersion makes the economy less efficient (see Schmitt-Grohé and Uribe, 2007). In the steady state, $s$ is increasing with inflation. The price dispersion effect, therefore, generates a negative inflation-output trade off, which clearly dominates the positive time-discounting effects even for extremely low steady state inflation rates, as is shown in Figure 1 (where the right hand side shows the trade-off for very low steady state inflation rates, while the left hand side does the same for somewhat higher rates).
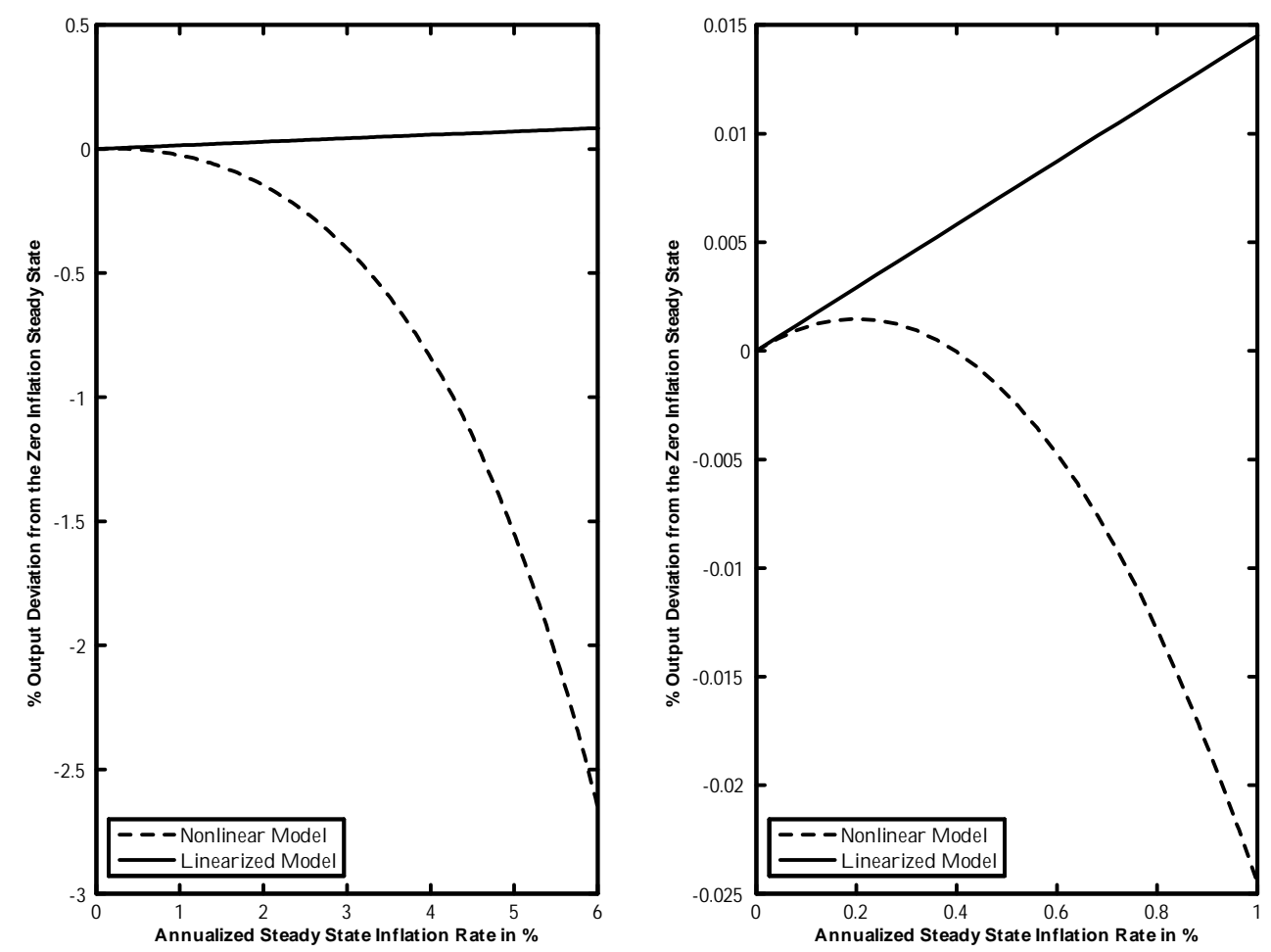

Figure 1: Relation between steady state inflation and output in the linearized and nonlinear model. 
In contrast, the vast majority of papers on the New Keynesian literature employ a version of the model log-linearized around a zero inflation steady state, which yields the standard New Keynesian Phillips curve: ${ }^{5}$

$$
\hat{\pi}_{t}=\beta E_{t} \hat{\pi}_{t+1}+\kappa \hat{y}_{t} .
$$

Dropping the time indices implies a weak positive long-run trade-off between inflation and output: $\hat{y}=\frac{1-\beta}{\kappa} \hat{\pi}$ (see Figure 1). This conclusion is an artifact due to the model being linearized around zero inflation. In this case, there is no price dispersion up to a first-order Taylor approximation. Thus, the price dispersion effect vanishes, and only the time-discounting effect remains, generating a positive inflation-output relationship. Indeed, the tangent at zero inflation to the curve implied by the true nonlinear model in Figure 1 exhibits a positive slope equal to $\frac{1-\beta}{\kappa}$.

\section{Real Wage Rigidities and Model Dynamics}

\subsection{Permanent Shock}

In this section, we look at a disinflation experiment, that is, an unanticipated and permanent reduction in the inflation target of the central bank, i.e., $\bar{\pi}$ in (4), say from $4 \%$ to $0 \%$.

Figure 2 shows the path for output, inflation, real wages, and the nominal interest rate in response to such a policy change in the log-linear model. ${ }^{6}$ In the absence of real wage rigidities, the model would immediately adjust to the new steady state, which implies a negligible output drop. There are no adjustment dynamics of real wages or inflation, and thus, no slump in output along the adjustment path.

\footnotetext{
${ }^{5} \kappa=(\sigma+\varphi) \frac{(1-\theta)(1-\beta \theta)}{\theta}$ under constant returns to labor. See Appendix.

${ }^{6}$ The model is log-linearized around a zero inflation steady state. The dynamic adjustment is obtained by assuming that the initial values of the variables correspond to steady state values of the $\log$-linear model at a permanent inflation rate of $4 \%$ (where all variables are expressed in terms of log-deviations from the zero inflation steady state). The Taylor rule becomes: $\hat{\imath}_{t}=\alpha_{\pi} \hat{\pi}_{t}+\alpha_{y} \hat{y}_{t}+\widehat{\bar{x}}^{4 \%}$, where $\widehat{\bar{x}}^{4 \%}=$ $\widehat{\bar{l}}^{4 \%}-\alpha_{\pi} \widehat{\bar{\pi}}^{4 \%}-\alpha_{y} \widehat{\widehat{y}}^{4 \%}$ summarizes the log-deviations of the targets from the zero inflation target. See Appendix for details.
} 

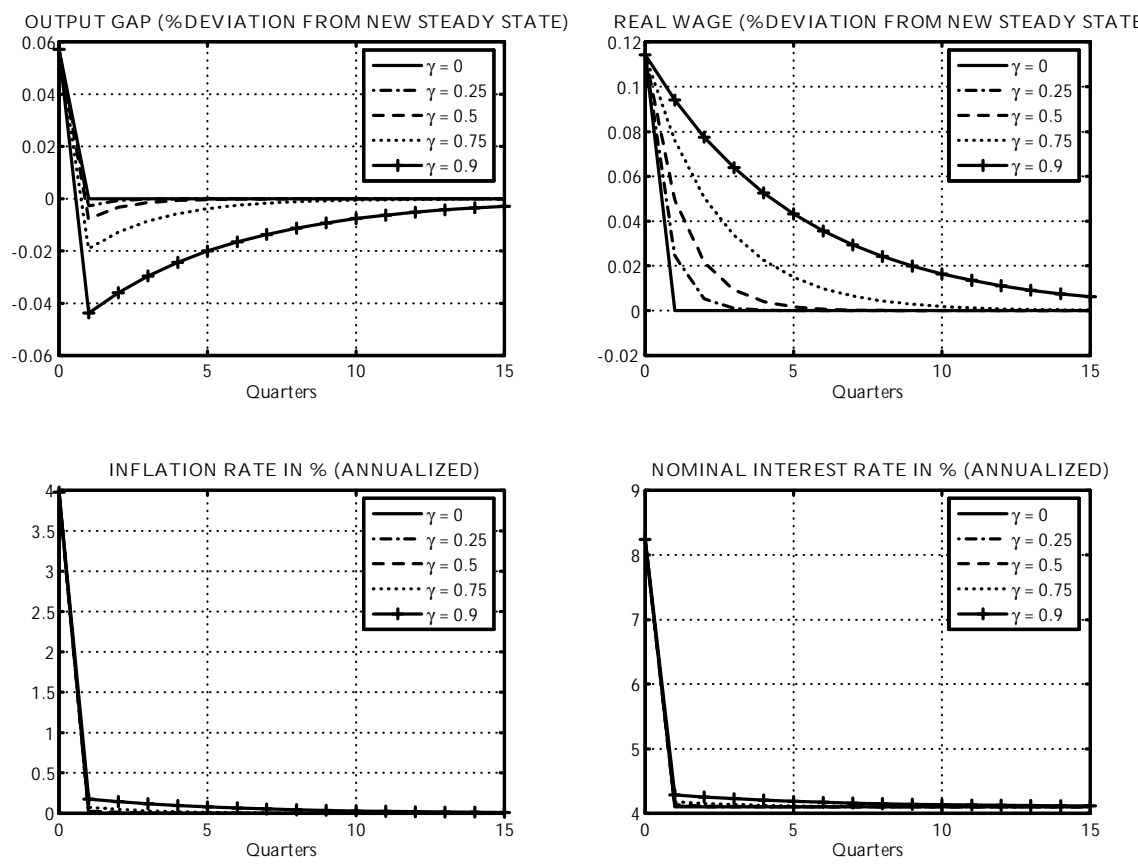

Figure 2: Permanent shock (disinflation from $4 \%$ to 0 ) in the linear model.
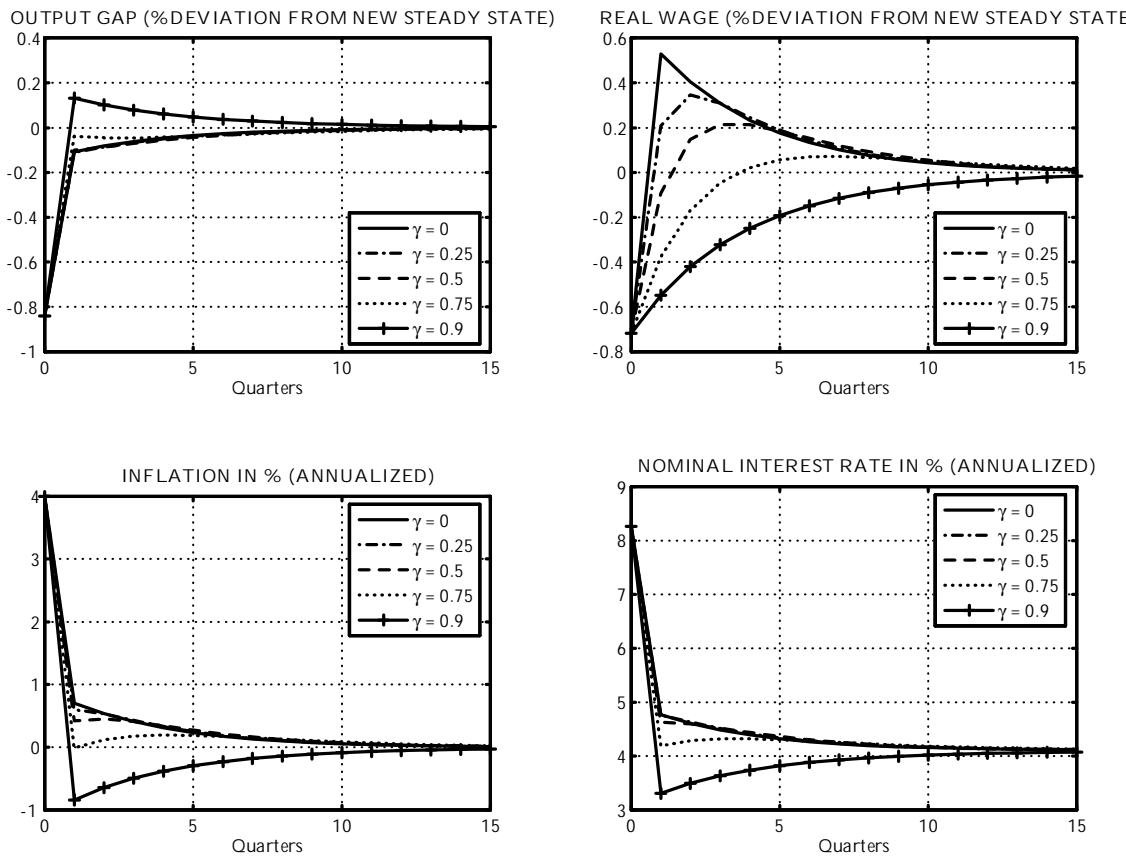

Figure 3: Permanent shock (disinflation from $4 \%$ to 0 ) in the nonlinear model. 
Introducing real wage rigidities in such a model, instead, generates sluggish real wages and, thus, a significant output slump along the adjustment path. These features become obviously more significant the higher the degree of real wage rigidity, i.e., the bigger $\gamma$. This is the type of result described, for example, in Section 4 in Blanchard and Galí (2007). Note, however, that real wage rigidities do not prevent a large initial drop in inflation towards the new long-run level.

Figure 3 shows that the adjustment path changes dramatically, instead, when nonlinear simulations are employed. ${ }^{7}$ First, the long-run equilibrium is radically different: after a disinflation from $4 \%$ to 0 , steady state output actually increases, rather than decreases, as in the log-linear model. Moreover, the steady state output change is now sizable. The opposite implication for the long-run behavior of the economy was already evident from Figure 1. Second, real wage rigidities have a striking implication: they actually tend to create a boom in output. Indeed, the higher the degree of real wage rigidities, the more likely the boom in output. That is, the implications of the inclusion of real wage rigidities are exactly the opposite for the dynamics of the linear vs. the nonlinear model.

The intuition for the completely different outcomes in the linear and nonlinear model is straightforward. It is due to the interplay between long-run effects and dynamic adjustment in the nonlinear model. In the nonlinear model, a disinflation, in fact, causes the real wage to increase in the long-run. A permanent decrease in the rate of inflation diminishes the price dispersion, $s$, in the long-run (see Figure 4). Given (5), a permanent decrease in $s$ acts as a permanent increase in labor productivity. Thus, for a given labor supply curve, the labor demand schedule shifts outwards and causes a permanent rise in the real wage. In the dynamic adjustment with no real wage rigidities, the real wage actually overshoots its new higher long-run equilibrium level, because of

\footnotetext{
${ }^{7}$ To simulate nonlinearly the impulse response functions, we used the software DYNARE, developed by Juillard at CEPREMAP. Impulse response functions are actually deterministic simulations: for a given path for the exogenous variable, one needs to find the response of the system, assuming that the initial values of the endogenous variables are at a steady state. As described in Boucekkine (1995) and Juillard (1996), DYNARE stacks up all the equations of the model for all the periods in the simulation (which we set equal to 100), and solves the resulting system en bloc by using the Newton-Raphson algorithm. Laffargue (1990) shows how this can be done by exploiting the special sparse structure of the Jacobian blocks.
} 
the strong reaction of consumption (i.e., output) to a permanent shock and of the slow adjustment of the price dispersion term $s$, since

$$
\frac{W_{t}}{P_{t}}=M R S_{t}=d_{n}(1+\varphi) s_{t}^{\varphi} Y_{t}^{\varphi+\sigma} .
$$

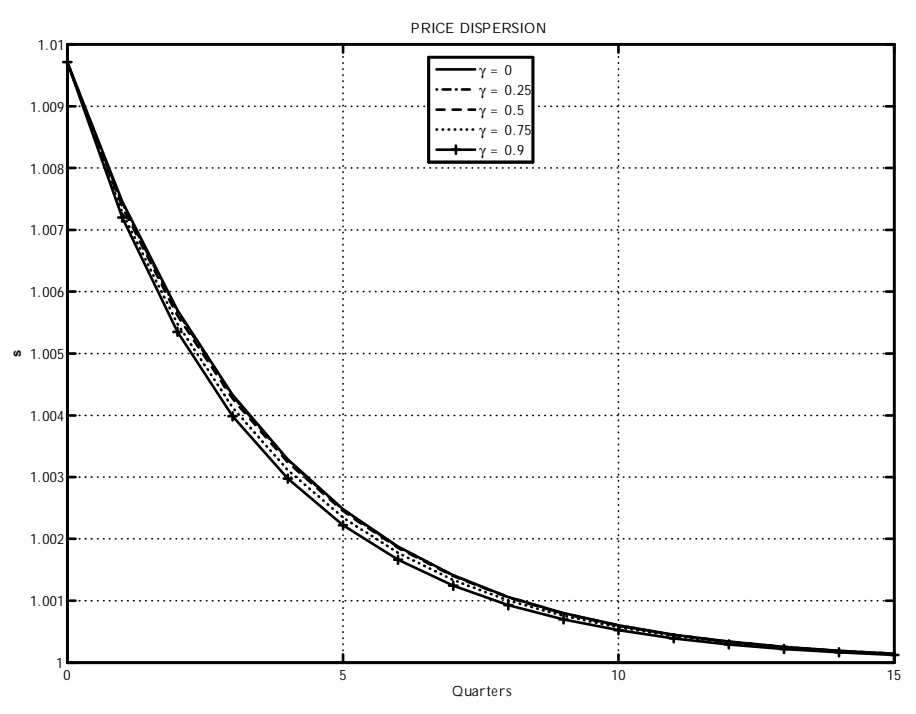

Figure 4: Development of price dispersion, $s_{t}$, in the nonlinear model.

Real wage rigidities, by construction, introduce a sluggish adjustment of the real wage in this adjustment process. It follows that the stronger the real wage rigidities are, the less the real wage will overshoot. The more muted adjustment path of the real wage tends to create a boom in output. Real wage rigidities basically transfer the overshooting from the real wage to output and inflation. Real wage rigidities imply neither inflation inertia on impact nor output costs after a disinflationary policy. ${ }^{8}$

\footnotetext{
${ }^{8}$ Finally, it is worth noting that one would obtain very similar results if a disinflation is envisaged as a sudden drop in inflation from $4 \%$ to $0 \%$, as in Blanchard and Galí (2007). Indeed, in our simulations, the path of inflation is very close to that. Results, however, would be different if a disinflation is implemented through a drop in the money supply growth rate. In this case, real wage rigidities amplify the output slump induced by the monetary policy shift, as was shown in an earlier version of this paper, available on our Webpages (for more on this, see Ascari and Ropele, 2007). However, what is important for the argument in this work is that under both experiments nonlinearities play a crucial role. This role is simply more evident under the experiment in this version of the paper. We thank an anonymous referee for drawing our attention to this issue.
} 
The intuition in the log-linear model, instead, goes exactly the other way around. A disinflation means a permanently lower level of output (due to the aforementioned discounting effect) and thereby reduces the real wage permanently. As the downward adjustment is more muted under real wage rigidities, they lead to an output slump. Although the latter may be more in line with empirical evidence, this result is a pure artefact of the log-linearization and does not correspond to the underlying micro-founded model.

\subsection{Temporary Shock}

Figures 5 and 6 show the impulse responses of the log-linear and the nonlinear model after a temporary negative shock to the inflation target, $\bar{\pi} \cdot{ }^{9}$ A negative temporary shock to the inflation target causes a monetary tightening that induces a slump in output, and a temporary reduction in inflation and the real wage. The higher the real wage rigidities, the more sluggish the adjustment in the real wage and in inflation is. The effects of the degree of real rigidities on output dynamics, however, are only marginal. The model's adjustment paths are in line with the role that real wage rigidities play in many of the papers mentioned in the introduction.

Figures 5 and 6 show that for this policy experiment the log-linear and the nonlinear model deliver very similar impulse response functions. They just differ slightly quantitatively. The message is that, as expected, the log-linear model is doing a pretty good job of approximating the model around a given steady state for sufficiently small shocks. ${ }^{10}$ Temporary shocks indeed do not imply a movement from a steady state to another one, as a permanent shocks do.

\footnotetext{
${ }^{9}$ The inflation target (initially at $0 \%$ ) is temporarily reduced by $1 \%$ during period 1 and follows an autoregressive process of first order (see Appendix for details on the calibration).

${ }^{10}$ The difference between the linear and the non-linear simulations becomes bigger with the size of the shock because the approximation implied by the log-linear model gets worse. However, this difference is still quantitatively negligible, as in Figure 5 and 6, even if we assume a $4 \%$ temporary shock to the inflation target (a sort of natural counterpart of the permanent shock in the previous Section). Hence, we prefer to show Figures 5 and 6 , which use a more common size $(1 \%)$ for the temporary shock.
} 

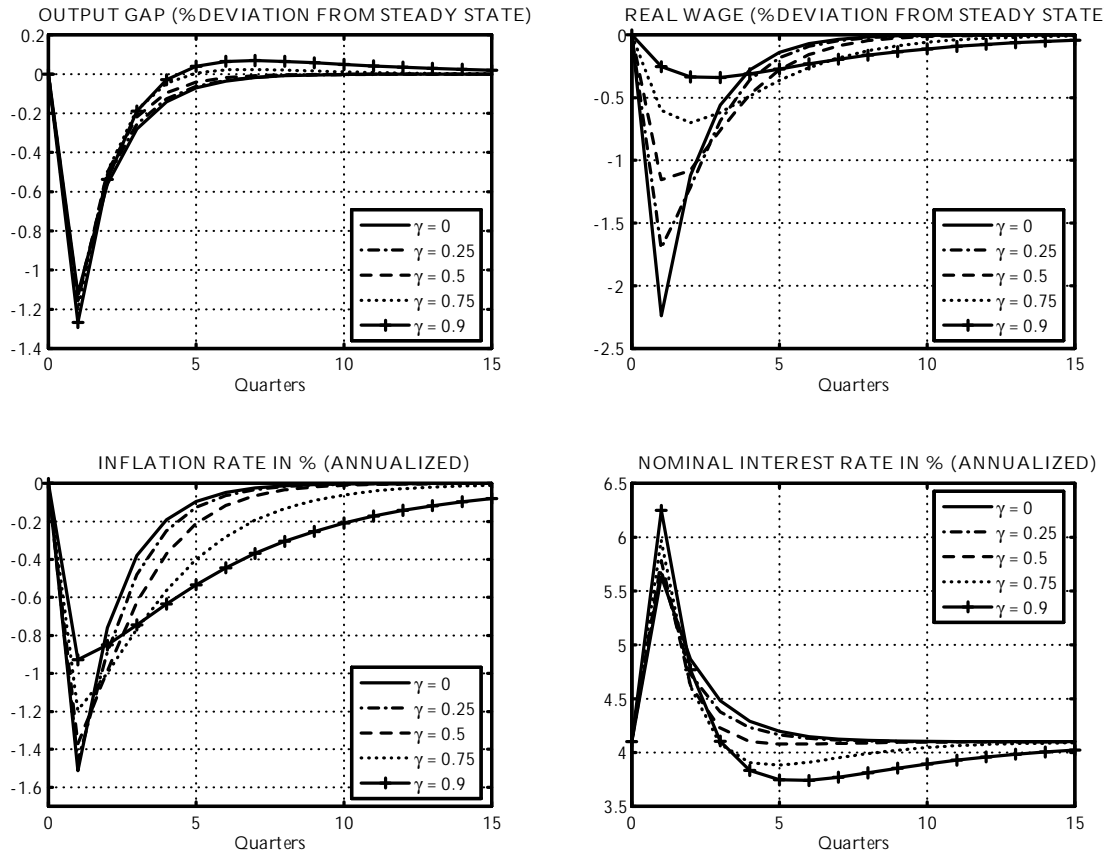

Figure 5: Temporary shock in the linear model.
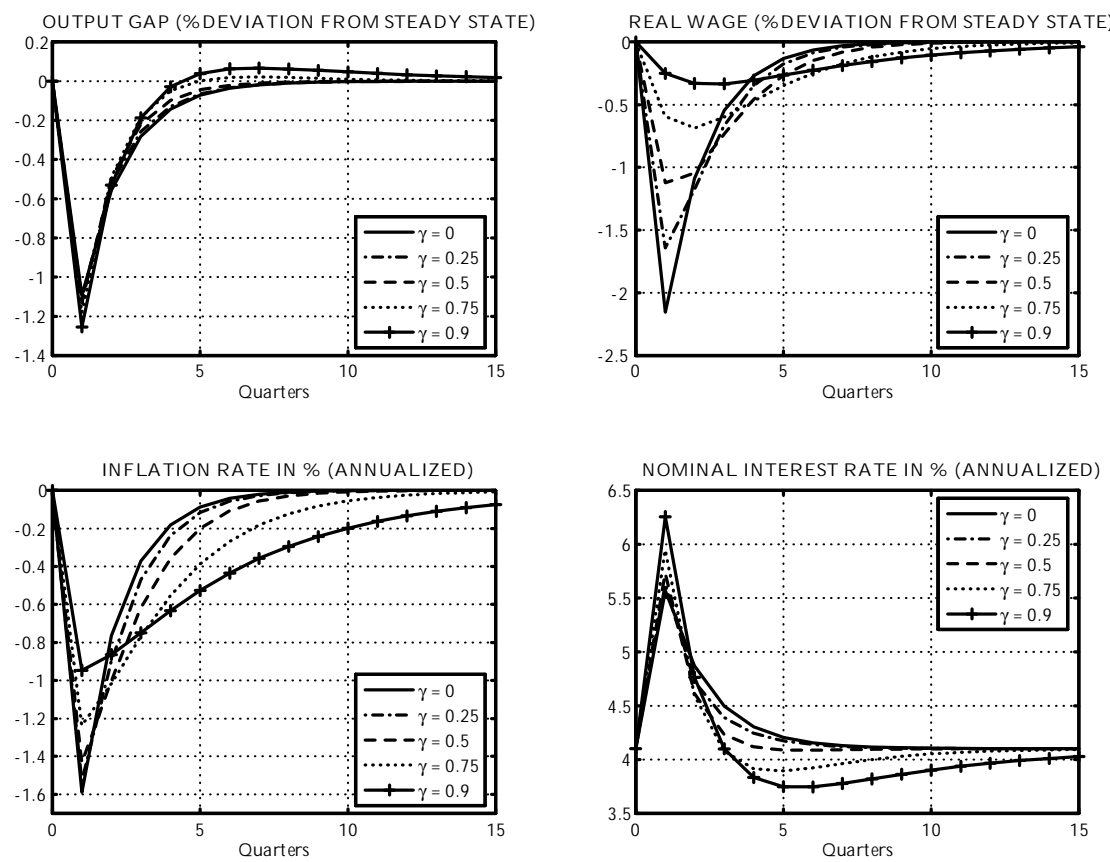

Figure 6: Temporary shock in the nonlinear model. 
The bottom line is that researchers, when using a model log-linearized around a particular steady state, should be very careful in extending results regarding temporary shocks to permanent shocks. This is particularly true for the standard New Keynesian model, which is very non linear around the zero inflation steady state (see Ascari, 2004). Therefore, adding new features to the model, as real wage rigidities, may have very different effects when looking at permanent or temporary monetary policy shocks.

\section{Conclusions}

This work shows that real wage rigidities cannot explain the cost of disinflations in the microfounded New Keynesian model. Actually, the higher the degree of real wage rigidities, the more likely a boom in output is, if the central bank permanently reduces the inflation target. The idea that real wage rigidities induce inertial inflation adjustment and thus can account for the output cost of disinflations is flawed because it does not take nonlinearities into account. Indeed, this idea is based on a log-linearized version of the model that is methodologically inaccurate, as the steady states change. Our analysis demonstrates that the interaction between long-run effects and short-run dynamics leads to completely different results in the log-linearized and in the nonlinear model. Real wage rigidities imply neither inflation persistence nor output costs after a disinflationary policy.

Researchers should be aware of the potentially big mistake of inferring the effects of permanent shocks through log-linearized models. The extent of this potential mistake obviously depends on how much nonlinearities matter, that is, how much nonlinear the original model is near the point around which the log-linearization is taken. This message is particularly important for the standard New Keynesian model, because it is very nonlinear around the zero inflation steady state, where it is commonly log-linearized in the literature.

\section{References}

Akerlof, George A. (1984): "Gift Exchange and Efficiency-Wage Theory: Four Reviews." American Economic Review, Vol. 74, No. 2, pp. 79-83. 
Ascari, Guido (2004): "Staggered Prices and Trend Inflation: Some Nuisances." Review of Economic Dynamics, Vol. 7, No. 3, pp. 642-667.

Ascari, Guido, and Ropele, Tiziano (2006): "Disinflation in New Keynesian Models." mimeo, University of Pavia.

Ball, Laurence, and Romer David (1990): "Real Rigidities and the Non-Neutrality of Money." Review of Economic Studies, Vol. 57, No. 2, pp. 183-203.

Bils, Mark, and Klenow, Peter (2004): "Some Evidence on the Importance of Sticky Prices." Journal of Political Economy, Vol. 112, No. 5, pp. 947-985.

Blanchard, Olivier, and Galí, Jordi (2007): "Real Wage Rigidities and the New Keynesian Model." Journal of Money, Credit, and Banking, Vol. 39, No. 1, Supplement, pp. 35-65.

Blanchard, Olivier, and Galí, Jordi (2006): "A New Keynesian Model with Unemployment." Massachusetts Institute of Technology, Department of Economics, Working Paper, No. 06-22, 18 July 2006.

Boucekkine, Raouf (1995): "An Alternative Methodology for Solving Nonlinear Forward-Looking Models." Journal of Economic Dynamics and Control, Vol. 19, No. 4, pp.711-734

Christoffel, Kai P., and Linzert, Tobias (2006): "The Role of Real Wage Rigidity and Labor Markt Frictions for Unemployment and Inflation Dynamics." Bundesbank Discussion Paper, Economic Research Centre: Series 1, No. 11/2006, April 2006.

Galí, Jordi (2003): "New Perspectives on Monetary Policy, Inflation, and the Business Cycle." In: Dewatriport, Mathias, Hansen, Lars P., and Turnovsky, Stephen J. (Eds), Advances in Economics and Econometrics: Theory and Applications, eighth World Congress, 2003, pp. 151-197.

Graham, Liam, and Snower, Dennis (2004): "The Real Effects of Money Growth in Dynamic General Equilibrium." ECB Working Paper Series, No. 412, November 2004. 
Hall, Robert (2005): "Employment Fluctuations with Equilibrium Wage Stickiness." American Economic Review, Vol. 95, No. 1, pp. 50-65.

Holden, Steinar (1994): "Wage Bargaining and Nominal Rigidities." European Economic Review, Vol. 38, No. 5, pp. 1021-1039.

Juillard, Michel (1996): "Dynare: A Program for the Resolution and Simulation of Dynamic Models with Forward Variables." CEPREMAP Working Paper, No. 9602.

Krause, Michael U., and Lubik, Thomas A. (2007): "The (Ir)relevance of Real Wage Rigidity in the New Keynesian Model with Search Frictions", Journal of Monetary Economics, Vol. 54, No. 3, pp. 706-727.

Laffargue, Jean-Pierre (1990): "Résolution d'un Modèle Macroéconomique avec Anticipations Rationnelles." Annales d'Économie et de Statistique, Vol. 17, pp. 97-119.

Oswald, Andrew J. (1979): "Wage Determination in an Economy with Many Trade Unions". Oxford Economic Papers, Vol. 31, pp. 369-385.

Schmitt-Grohé, Stephanie, and Uribe, Martín (2007): "Optimal Simple and Implementable Monetary and Fiscal Rules." Journal of Monetary Economics, forthcoming.

Yun, Tack (2005): "Optimal Monetary Policy with Relative Price Distortions." American Economic Review, Vol. 95, No. 1, pp. 89-109. 


\section{Appendix}

\section{Model Setup}

\section{Household}

The instantaneous utility function is assumed to be separable

$$
U\left(C_{t}(h), N_{t}(h)\right)=\frac{C_{t}^{1-\sigma}}{1-\sigma}-d_{n} \frac{N_{t}^{1+\varphi}(h)}{1+\varphi},
$$

and the period by period budget constraint is given by

$$
P_{t} C_{t}+\left(1+i_{t}\right)^{-1} B_{t}=W_{t} N_{t}-T_{t}+D_{t}+B_{t-1},
$$

where $i_{t}$ is the nominal interest rate, $B_{t}$ is one-period bond holdings, $W_{t}$ is the nominal wage rate, $N_{t}$ is the labor input, $T_{t}$ is lump sum taxes, and $D_{t}$ is the profit income. The representative consumer problem, maximizing the expected discounted (using the discount factor $\beta$ ) intertemporal utility subject to the budget constraints, yields the following first-order conditions

$$
\begin{aligned}
& \text { Euler equation : } \frac{1}{C_{t}^{\sigma}}=\beta E_{t}\left[\left(\frac{P_{t}}{P_{t+1}}\right)\left(1+i_{t}\right)\left(\frac{1}{C_{t+1}^{\sigma}}\right)\right], \\
& \text { Labor supply equation } \frac{W_{t}}{P_{t}}=-\frac{U_{N}}{U_{C}}=\frac{d_{n} N_{t}^{\varphi}}{1 / C_{t}^{\sigma}}=d_{n} N_{t}^{\varphi} C_{t}^{\sigma} .
\end{aligned}
$$

We introduce real wage rigidities, by changing this last equation to

$$
\frac{W_{t}}{P_{t}}=\left(\frac{W_{t-1}}{P_{t-1}}\right)^{\gamma} M R S_{t}^{1-\gamma}=\left(\frac{W_{t-1}}{P_{t-1}}\right)^{\gamma}\left(-\frac{U_{N_{t}}}{U_{C_{t}}}\right)^{1-\gamma},
$$

where $\gamma$ measures the degree of real wage rigidities.

\section{Technology}

Final good producers use the following technology

$$
Y_{t}=\left[\int_{0}^{1} Y_{i, t}^{\frac{\varepsilon-1}{\varepsilon}} d i\right]^{\frac{\varepsilon}{\varepsilon-1}} .
$$

Their demand for intermediate inputs is therefore equal to $Y_{i, t+j}=\left(\frac{P_{i, t}}{P_{t+j}}\right)^{-\varepsilon} Y_{t+j}$.

The production function of intermediate goods producers is

$$
Y_{i, t}=N_{i, t}^{1-\alpha}
$$

The labor demand and the real marginal cost of firm $i$ is therefore

$$
N_{i, t}^{d}=\left[Y_{i, t}\right]^{\frac{1}{1-\alpha}}
$$


and

$$
M C_{i, t}^{r}=\frac{1}{1-\alpha} \frac{W_{t}}{P_{t}} Y_{i, t}^{\frac{\alpha}{1-\alpha}} .
$$

Note that now marginal costs depend upon the quantity produced by the single firm, given the decreasing returns to scale. In other words, different firms charging different prices would produce different levels of output and hence have different marginal costs

$$
M C_{i, t}^{r}=\frac{1}{1-\alpha} \frac{W_{t}}{P_{t}}\left[\left(\frac{P_{i, t}}{P_{t}}\right)^{-\varepsilon} Y_{t}\right]^{\frac{\alpha}{1-\alpha}} .
$$

\section{Firms' Pricing}

The price-resetting problem of an intermediate producer is hence

$$
\begin{gathered}
\max _{P_{i, t}} E_{t} \sum_{j=0}^{\infty} \theta^{j} \Delta_{t, t+j}\left[\frac{P_{i, t}}{P_{t+j}} Y_{i, t+j}-T C_{t+j}^{r}\left(Y_{i, t+j}\right)\right] \\
\text { s.t. } Y_{i, t+j}=\left(\frac{P_{i, t}}{P_{t+j}}\right)^{-\varepsilon} Y_{t+j},
\end{gathered}
$$

where $P_{i, t}$ denotes the new optimal price of producer $i, T C_{t+j}^{r}\left(Y_{i, t+j}\right)$ the real total cost function, and $\Delta_{t, t+j}$ the stochastic discount factor (from period $t$ to period $t+j$ ). The solution to this problem yields the familiar formula for the standard optimal resetted price in a Calvo setup

$$
P_{i, t}=\left(\frac{\varepsilon}{\varepsilon-1}\right) \frac{E_{t} \sum_{j=0}^{\infty} \theta^{j} \Delta_{t, t+j}\left[P_{t+j}^{\varepsilon} Y_{t+j} M C_{i, t+j}^{r}\right]}{E_{t} \sum_{j=0}^{\infty} \theta^{j} \Delta_{t, t+j}\left[P_{t+j}^{\varepsilon-1} Y_{t+j}\right]} .
$$

Using (17), we can re-write equation (20) as

$$
\begin{gathered}
\left(\frac{P_{i, t}}{P_{t}}\right)^{1+\frac{\varepsilon \alpha}{1-\alpha}}=\left(\frac{\varepsilon}{\varepsilon-1}\right)\left(\frac{\psi_{t}}{\phi_{t}}\right) \\
\psi_{t}=E_{t} \sum_{j=0}^{\infty}(\theta \beta)^{j} u_{c}(t+j)\left[\Pi_{t, t+j}^{\frac{\varepsilon}{1-\alpha}} Y_{t+j}^{\frac{1}{1-\alpha}} \frac{1}{1-\alpha} w_{t+j}\right] \\
\phi_{t}=E_{t} \sum_{j=0}^{\infty}(\theta \beta)^{j} u_{c}(t+j)\left[\Pi_{t, t+j}^{\varepsilon-1} Y_{t+j}\right]
\end{gathered}
$$

where $\prod_{t, t+j}^{z}=\pi_{t+1}^{z} \pi_{t+2}^{z} \ldots \pi_{t+j}^{z}=\prod_{i=1}^{j} \pi_{t+i}^{z}$ for $j \geq 1$ and equal one for $j=0, z$ is a power, and $\pi_{t}=P_{t} / P_{t-1}$. This allows us to write (22) and (23) recursively, to obtain

$$
\psi_{t}=\frac{1}{1-\alpha} u_{c}(t) Y_{t}^{\frac{1}{1-\alpha}} w_{t}+\theta \beta E_{t}\left(\pi_{t+1}^{\frac{\varepsilon}{1-\alpha}} \psi_{t+1}\right)
$$




$$
\phi_{t}=u_{c}(t) Y_{t}+\theta \beta E_{t}\left[\pi_{t+1}^{\varepsilon-1} \phi_{t+1}\right] .
$$

The aggregate price level evolves according to

$$
P_{t}=\left[\int_{0}^{1} P_{i, t}^{1-\varepsilon} d i\right]^{\frac{1}{1-\varepsilon}} \Longrightarrow 1=\left[\theta \pi_{t}^{\varepsilon-1}+(1-\theta)\left(\frac{P_{i, t}}{P_{t}}\right)^{1-\varepsilon}\right]^{\frac{1}{1-\varepsilon}} .
$$

\section{Aggregation and Price Dispersion}

The aggregate resource constraint is simply given by

$$
Y_{t}=C_{t}
$$

and, as shown in the main text, the link between aggregate labor demand and aggregate output is provided by

$$
N_{t}^{d}=\left[Y_{t}\right]^{\frac{1}{1-\alpha}} \underbrace{\int_{0}^{1}\left[\left(\frac{P_{i, t}}{P_{t}}\right)^{-\varepsilon}\right]^{\frac{1}{1-\alpha}} d i}_{s_{t}}=s_{t}\left[Y_{t}\right]^{\frac{1}{1-\alpha}} .
$$

Schmitt-Grohé and Uribe (2007) show that $s_{t}$ is bounded below at one, so that $s_{t}$ represents the resource costs due to relative price dispersion (under the Calvo mechanism) with long-run inflation. Indeed, the higher $s_{t}$, the more labor is needed to produce a given level of output. $s_{t}$ does not affect the real variables up to the first order whenever there is no trend inflation (i.e., $\bar{\pi}_{t}=1$ ).

To close the model, we just need to solve for the dynamic of $s$, that is

$$
s_{t}=(1-\theta)\left[\frac{P_{i, t}}{P_{t}}\right]^{-\frac{\varepsilon}{1-\alpha}}+\theta \pi_{t}^{\frac{\varepsilon}{1-\alpha}} s_{t-1}
$$

\section{Monetary Policy}

The central bank follows a standard Taylor rule, with the weight $\alpha_{\pi}$ on deviations of inflation from the target level and the weight $\alpha_{y}$ on output deviations, i.e.,

$$
\left(\frac{1+i_{t}}{1+\bar{\imath}}\right)=\left(\frac{\pi_{t}}{\bar{\pi}}\right)^{\alpha_{\pi}}\left(\frac{Y_{t}}{\bar{Y}}\right)^{\alpha_{y}}
$$

\section{System of Equations}


The following systems of equations are simulated nonlinearly: Equations (10), (11), (21), (24), (25), (26), (27), (28), (29), and (30).

In the presence of a real wage rigidity, equation (11) is replaced by equation (12).

\section{The Log-Linear Model}

The linear model is obtained by log-linearizing the original equations around the zero inflation steady state. The variables are expressed in terms of log-deviations from the zero inflation steady state (denoted by ${ }^{\wedge}$ ). The model equations are: the Phillips curve, the Euler equation and the labor supply/real wage rigidities equation (where $\hat{w}_{t}^{r}$ denotes the real wage).

$$
\begin{gathered}
\hat{\pi}_{t}=\beta \hat{\pi}_{t+1}+\frac{(1-\theta)(1-\beta \theta)(1-\alpha)}{\theta[1+\alpha(\varepsilon-1)]} \hat{w}_{t}^{r}, \\
\hat{y}_{t}=E_{t}\left(\hat{y}_{t+1}\right)-\frac{1}{\sigma}\left(\hat{\imath}_{t}-E_{t}\left(\hat{\pi}_{t+1}\right)\right), \\
\hat{w}_{t}^{r}=\gamma \hat{w}_{t-1}^{r}+(1-\gamma)(\sigma+\varphi) \hat{y}_{t} .
\end{gathered}
$$

The steady state of such a model thus is

$$
\begin{gathered}
\hat{w}^{r}=(\sigma+\varphi) \hat{y}, \\
\hat{\pi}=\frac{\kappa}{1-\beta} \hat{y}, \\
\hat{\imath}=\hat{\pi},
\end{gathered}
$$

where $\kappa \equiv \frac{(1-\theta)(1-\beta \theta)(1-\alpha)}{\theta[1+\alpha(\varepsilon-1)]}(\sigma+\varphi)$, and all the variables are in log-deviations from the zero inflation steady state level. Given a steady state level of inflation (e.g., $4 \%$ annual inflation would be $\left.\hat{\pi}^{4 \%}=\ln \left(1.04^{1 / 4}\right)\right)$, we can hence easily calculate the corresponding steady state values for $\hat{y}, \hat{w}^{r}$ and $\hat{r}$, and use them as initial values for our disinflation experiment.

In the Taylor rule, instead, variables are expressed as deviations from the target. Therefore, given a generic non-zero inflation rate target $(\bar{\pi})$, the logarithm of the Taylor rule is

$$
\ln \left(\frac{1+i_{t}}{1+\bar{\imath}}\right)=\alpha_{\pi} \ln \left(\frac{\pi_{t}}{\bar{\pi}}\right)+\ln \alpha_{y}\left(\frac{Y_{t}}{\bar{Y}}\right)
$$

which is by definition an identity at the steady state (where targets are met). (37) can be transformed by defining the variables as deviations from the zero inflation rate steady 
state in the following simple way:

$$
\begin{aligned}
\ln \left(\frac{1+i_{t}}{1+\bar{\imath}^{0 \%}} \frac{1+\bar{\imath}^{0 \%}}{1+\bar{\imath}}\right) & =\alpha_{\pi} \ln \left(\frac{\pi_{t}}{\bar{\pi}^{0 \%}} \frac{\bar{\pi}^{0 \%}}{\bar{\pi}}\right)+\ln \alpha_{y}\left(\frac{Y_{t}}{\bar{Y}^{0 \%}} \frac{\bar{Y}^{0 \%}}{\bar{Y}}\right) \Longrightarrow \\
& \Longrightarrow \hat{\imath}_{t}=\alpha_{\pi} \hat{\pi}_{t}+\alpha_{y} \hat{y}_{t}+\widehat{\bar{x}}
\end{aligned}
$$

where $\widehat{\bar{x}} \equiv \widehat{\bar{\imath}}-\alpha_{\pi} \widehat{\bar{\pi}}-\alpha_{y} \widehat{\bar{y}}$ summarizes the log-deviations of the targets from the zero inflation target. Our disinflation experiment is an unanticipated and permanent reduction in the inflation target from $4 \%$ to zero. Hence this determines the initial value of $\widehat{\bar{x}}$ to be $\widehat{\bar{x}}^{4 \%}=\widehat{\bar{\imath}}^{4 \%}-\alpha_{\pi} \widehat{\bar{\pi}}^{4 \%}-\alpha_{y} \widehat{\widehat{y}}^{4 \%}$, and then a permanent jump of $\widehat{\bar{x}}$ to zero.

\section{Steady State Calculations}

The steady state values in the non-stochastic steady state can simply be obtained by dropping the time indices. The steady state inflation is equal to the central bank's inflation target: $\pi=\bar{\pi}$. By defining $x=\frac{P_{i}}{P}$, equation (26) determines the steady state relative price of firms which are able to reset the price

$$
x=\left(\frac{1-\theta \bar{\pi}^{\varepsilon-1}}{1-\theta}\right)^{\frac{1}{1-\varepsilon}}
$$

which in turn pins down the price dispersion in the economy from (29)

$$
s=\frac{(1-\theta) x^{-\frac{\varepsilon}{1-\alpha}}}{1-\theta \bar{\pi}^{\frac{\varepsilon}{1-\alpha}}} .
$$

Then (24), (25) and (21) become, respectively

$$
\begin{aligned}
\psi & =\frac{\frac{1}{1-\alpha} w Y^{\frac{1}{1-\alpha}-\sigma}}{1-\theta \beta \bar{\pi}^{\frac{\varepsilon}{1-\alpha}}}, \\
\phi & =\frac{Y^{1-\sigma}}{1-\theta \beta \bar{\pi}^{(\varepsilon-1)}}, \\
x^{1+\varepsilon \frac{\alpha}{1-\alpha}}=\left(\frac{\varepsilon}{\varepsilon-1}\right)\left(\frac{\psi}{\phi}\right) & =\left(\frac{\varepsilon}{\varepsilon-1}\right)\left(\frac{1-\theta \beta \bar{\pi}^{(\varepsilon-1)}}{1-\theta \beta \bar{\pi}^{\frac{\varepsilon}{1-\alpha}}}\right) \frac{1}{1-\alpha} w Y^{\frac{\alpha}{1-\alpha}} .
\end{aligned}
$$

Equation (11) can be re-written as

$$
w=d_{n} N^{\varphi} C^{\sigma}=d_{n} s^{\varphi} Y^{\sigma+\frac{\varphi}{1-\alpha}} .
$$

Substituting it into (44) yields an expression for output as a function of $\bar{\pi}$ and $s$

$$
Y=\left(x^{\frac{1-\alpha+\varepsilon \alpha}{1-\alpha}} \frac{(1-\alpha)(\varepsilon-1)\left(1-\theta \beta \bar{\pi}^{\frac{\varepsilon}{1-\alpha}}\right)}{\varepsilon\left(1-\theta \beta \bar{\pi}^{(\varepsilon-1)}\right) d_{n}} s^{-\varphi}\right)^{\frac{1-\alpha}{\varphi+\sigma+\alpha(1-\sigma)}}
$$


Substituting equations (40) and (41) into (46) delivers an equation for the long-run trade-off between inflation and output, that we use to plot Figure 1 in the main text.

\section{Calibration of the Model}

$d_{n}$ is calibrated in such a way that people devote one third of their time to work (under zero steady state inflation). The elasticity of substitution between different product types, $\varepsilon$, is set to 10 . We use a standard quarterly discount rate of one percent, $\beta=0.99$, a log-utility of consumption, $\sigma=1$, and a quadratic disutility of labor, $\varphi=1$ (see, e.g., Galí, 2003). The quarterly probability of not re-setting the prices, $\theta$, is set to 75 percent, as in most of the calibrations in the literature. ${ }^{11}$

As usual in the literature, we set the coefficients in the Taylor rule as follows: $\alpha_{\pi}=$ 1.5 and $\alpha_{y}=0.5$. In order to make our results comparable to the existing literature, under a temporary shock to the inflation target, we assume an autoregressive process of first order, namely

$$
\ln \bar{\pi}_{t}=\rho \ln \bar{\pi}_{t-1}+\varepsilon_{t}
$$

for the linear model, and

$$
\bar{\pi}_{t}=\bar{\pi}_{t-1}^{\rho} \exp \varepsilon_{t}
$$

for the nonlinear model, where $\varepsilon_{t}$ is an i.i.d. shock. We set the autoregressive parameter to $\rho=0.5$.

\footnotetext{
${ }^{11}$ Note that setting the average price duration to two quarters (corresponding to the results in Bils and Klenow, 2004) does not affect our qualitative outcomes.
} 